\title{
THEORETICAL ASSESSMENT OF A STIRLING ENGINE 'AMAZON' BY USING PROSA AND MATHCAD
}

\author{
R. B. Paula, \\ J. L. Goncalves ${ }^{b}$, \\ V. R. M. Cobas', \\ and Electo E. S. Lorad \\ Universidade Federal de Itajubá \\ Instituto de Engenharia Mecânica \\ Av. BPS - N 1303, Pinheirinho \\ CP. 50, Itajubá, Minas Gerais, Brasil \\ arafael.bergamasco@gmail.com \\ bjoseluiz@unifei.edu.br \\ cvlad@unifei.edu.br \\ delecto@unifei.edu.br
}

\section{ABSTRACT}

This study describes how to build a prototype Stirling engine named Amazon, focusing on how to apply it to generate electric power in remote areas, with an expected power of $8 \mathrm{~kW}$. Such engine was assessed theoretically by using two different computer software, i.e. PROSA and 'a model to simulate Stirling engines by the theory of Schmidt', which was formulated in Mathcad. The results from Mathcad software were on average $6.8 \%$ higher than the results from PROSA software. Such fact occurs since Mathcad does not consider the losses in a real system. Hence, the PROSA is generally more accurate in its results. Modeling performed in Mathcad presents higher values for partial loads and similar values for the project operating point.

Keywords: Theoretical assessment; Stirling engines; PROSA; Mathcad; Simulation

\section{INTRODUCTION}

Growth and diversification of energy sources to provide more electricity for population has created new technologies to produce energy. Nowadays, Stirling engines has become research target in this area (Minassians and Sanders, 2009; Betts 2009; Mahkamov 2006a, 2007b) since the advances in manufacturing technology for such engines, materials and sealing systems has provided this. Such external combustion engine feature allows the use of several fuels, since all needs are only a high temperature source, also making use solar energy as heat source (Minassians and Sanders, 2009).

Since to assess such engines experimentally takes time and money, the theoretical assessment could facilitate testing the feasibility to use such engines (Cullen and McGovern, 2010; Mahkamov, 2006a, 2007b; Rogdakis et al 2002; Thomas, 2003). In this wise, the main goal of this simulation is look for the best theoretical condition and efficiency of a Stirling engine prototype using the PROSA and Mathcad.

\section{SIMULATION AND EXPERIMENTAL PROCEDURE}

\section{Characteristics of the Stirling Engine $8 \mathrm{~kW}$ Amazon}

The designed Stirling engine was built to be applied in isolated regions, and one of the criteria to select its properties was to determine the power range required by the generation system in the region to be applied. For example, data from a cataloguing in the Amazon region of the State of Acre (Juruá river valley, Brazil), showed 240 communities for a median of 13 domiciles per community, and $40 \%$ of such communities have until six domiciles (Azzur 2005). Electricity demand is therefore $50-10 \mathrm{~kW}$ per community.

Concerning the selection of drive unit, among the types of Stirling engines, we chose to the alpha ( $\alpha$ ) model, since it is the configuration similar to some blocks of motorcycles and air compressors easily found in the market. We used a motorcycle engine block Cagiva model (Ducati), and it has all the technical requirements to work as the primary drive for a Stirling engine of $8 \mathrm{~kW}$. The main technical engine data built is in Tab. 1. For converting the Ducati engine operation to Stirling engine of $8 \mathrm{~kW}$, some adaptations had been performed, as shown in Tab. 1.

The left part of Fig. 1 shows the Stirling engine $8 \mathrm{~kW}$ without the necessary adaptations, which can be seen in the sketch on the right. After reassembling the engine, the experimental data to be obtained will be compared with theoretical data in this work.

\section{Modeling by PROSA software}

The PROSA (second order Assessment Software) is a software to assess machines based on a regenerative gas cycle, which can be used to assess Stirling engines in sundry configurations, e.g. engines for alpha, beta and gamma, and Siemens configuration. The application varies between: (a) primary drive, (b) cooling machine and (c) heat pump. Different types of heat exchangers, regenerators and working gas can be chosen, as well as crankshaft and free piston machines.

A routine change for parameters and optimization contains the software to design Stirling engines with optimized performance. 
Table 1. Preliminary technical engine data of $8 \mathrm{~kW}$ power.

\begin{tabular}{|c|c|}
\hline \multicolumn{2}{|c|}{ Mobile parts } \\
\hline Piston diameter & $167 \mathrm{~mm}$ \\
\hline Piston stroke expansion & $68 \mathrm{~mm}$ \\
\hline Compression piston diameter & $167 \mathrm{~mm}$ \\
\hline Expansion piston length & $200 \mathrm{~mm}$ \\
\hline $\begin{array}{l}\text { Space between piston and } \\
\text { cylinder }\end{array}$ & $1 \mathrm{~mm}$ \\
\hline $\begin{array}{c}\text { Final separation at the top of } \\
\text { piston (expansion) }\end{array}$ & $1 \mathrm{~mm}$ \\
\hline $\begin{array}{l}\text { Final separation at the top of } \\
\text { piston (compression) }\end{array}$ & $1 \mathrm{~mm}$ \\
\hline $\begin{array}{c}\text { Phase difference between } \\
\text { expansion pistons and } \\
\text { compression pistons }\end{array}$ & $90^{\circ}$ \\
\hline $\begin{array}{l}\text { Working gas temperature } \\
\text { inside the heater }\end{array}$ & $630^{\circ} \mathrm{C}$ \\
\hline $\begin{array}{l}\text { Working gas temperature } \\
\text { inside the heater }\end{array}$ & $630^{\circ} \mathrm{C}$ \\
\hline Absolute mean pressure & 40 bar \\
\hline Maximum speed & $1,500 \mathrm{rpm}$ \\
\hline \multicolumn{2}{|c|}{ Data from the hot heat exchanger (heater) } \\
\hline Material & AISI-310 (1.4841) \\
\hline Quantity of finned tubes & 100 \\
\hline Internal diameter & $5 \mathrm{~mm}$ \\
\hline Length & $500 \mathrm{~mm}$ \\
\hline $\begin{array}{l}\text { Hydrodynamic loss } \\
\text { coefficient for input stream }\end{array}$ & 1.5 \\
\hline \multicolumn{2}{|c|}{ Data from the hot heat exchanger (heater) } \\
\hline Material & AISI-310 (1.4841) \\
\hline Quantity of finned tubes & 70 \\
\hline Internal diameter & $5 \mathrm{~mm}$ \\
\hline Length & $300 \mathrm{~mm}$ \\
\hline $\begin{array}{l}\text { Hydrodynamic loss } \\
\text { coefficient for input stream }\end{array}$ & 1.5 \\
\hline \multicolumn{2}{|c|}{ Cold side connection channels } \\
\hline Quantity & 1 \\
\hline Internal diameter & $18 \mathrm{~mm}$ \\
\hline Length & $50 \mathrm{~mm}$ \\
\hline $\begin{array}{l}\text { Hydrodynamic loss } \\
\text { coefficient for input stream }\end{array}$ & 1.5 \\
\hline
\end{tabular}

The software structure, in addition, is modular, to allow addition of components, e.g. a new heat exchanger, or regenerator configurations, or other thermodynamic cycles, without great efforts (Thomas, 2003).

By using a common second-order model, the Stirling engine can be divided into five volumes: two cylinders, two heat exchangers and one regenerator. The mean working gas temperature is considered constant for each cylinder and heat exchanger. The temperature profile in the regenerator is approximated by a linear function. Such considerations create minimum deviations for cylinders and heat exchangers. Thus, one does not need to include additional modules to separate finite elements.

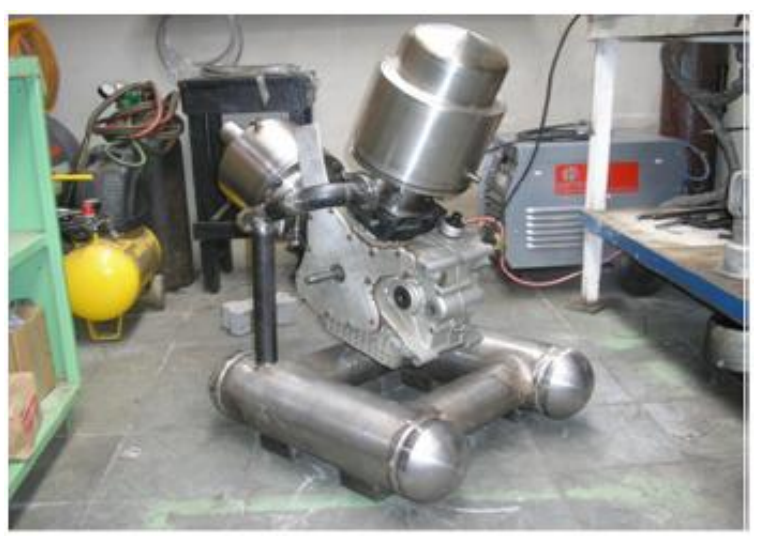

(a)

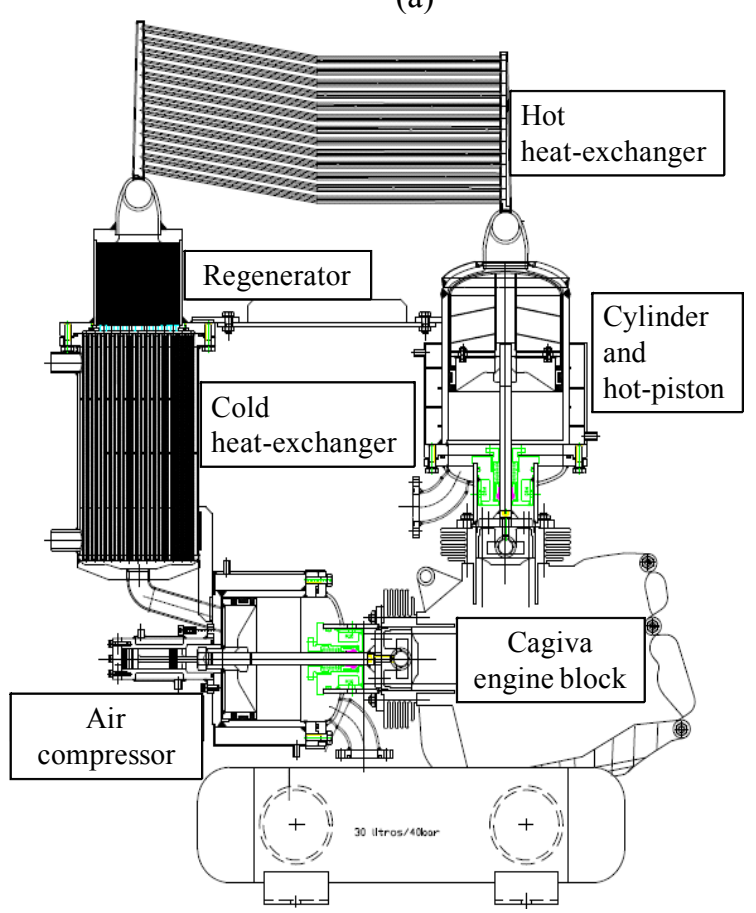

(b)

Figure 1. (a) Picture and (b) simplified general scheme for the adaptations required by the Ducati engine block to operate as a Stirling engine of $8 \mathrm{~kW}$ power.

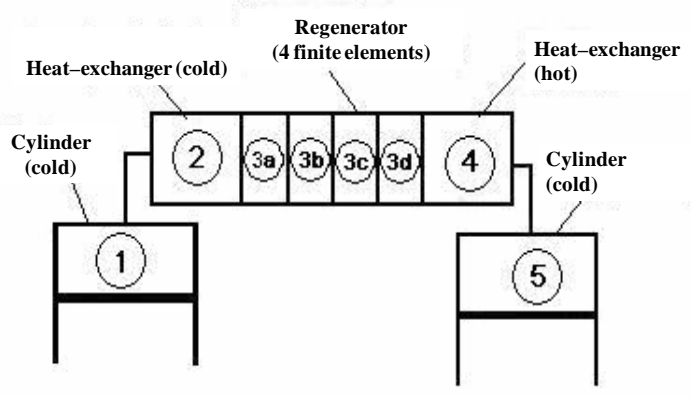

Figure 2. Division of the Stirling engine in different volumes or finite element to the PROSA software (Adapted from Thomas, 2003). 
Concerning the temperature profile in the regenerator, it significantly differs in a real machine of a linear function, which requires a closer look. The model used in the regenerator PROSA, for this reason, consists of four finite elements, as illustrated in the Fig. 2. Such elements encourage a good relation for the rise in accuracy of calculated results and in model complexity, requiring a large computational time.

A second order model, as mentioned, includes a loss assessment after each calculation for the thermodynamic cycle. The final results depend heavily on the accuracy of such loss assessment. In recent years, researchers have strived to obtain solutions suitable for different types of losses in the Stirling engine. The main losses assessed by PROSA are heat transfer losses: in heat exchangers and cylinders; in regenerator, by heat conduction along the regenerator and cylinder to the crankcase; in connections among parts of the engine; in adiabatic; by pressure drop (load loss) in heat exchangers and regenerator; by friction in the piston seals, etc.

Because of this additional loss assessment, the initial conditions of the thermodynamic cycle related to the working gas temperature are affected, requiring an iterative procedure. Mathematically, this iteration is done by using a non-linear system with an energy balance for each volume and balance of mechanical energy. It requires the gas and rotation mean temperature or mechanical power as iteration variables. The system is solved by Newton's method with partial derivatives of certain numerically nonlinear equations.

To define the input data in the PROSA, technical drawings from the building project of Amazon engine of $8 \mathrm{~kW}$ were used. When starting the software, two initial windows are displayed. At the first one, named 'cycle 1 configuration', one must choose the (a) type of application (primary drive, refrigerator, heat pump), (b) cylinder configuration (alpha, beta, gamma), and (c) piston movement (sinusoidal or free piston). In the second window (cycle 2 configuration) appears the options: (a) type of heat exchangers (hot and cold; if they are smooth or finned tubes, without exchangers, etc.), (b) type of regenerator (wire mesh, wings or fins), and (c) type of working fluid (hydrogen, helium or air).

The next window consists of seven tabs, in which all the technical engine data are introduced. We considered hugely important the data entry for the regenerator, in particular for the wire diameter, quantity of layers, and size of wire mesh. In doing so, we tried to find appropriate mesh porosity, i.e. without causing an excessive load or compromising the engine efficiency.

\section{Modeling by Mathcad software}

This software was initially used to define the dimensions and performance characteristics previously, needed to start developing the project and building such Amazon engine. The calculation algorithm used by the software is based on the theory of Gustav Schmidt. He developed the first theoretical assessment for Stirling engines in 1871. This became a classical assessment for the cycle, being useful to result in a reasonable approximation to the engine performance. However, since it is a theoretical assessment, some assumptions and simplifications are performed, and in practice, the engine performance is often less than $60 \%$ of the anticipated performance concerning theory of Schmidt (Rogdakis, 2002).

\section{SIMULATION AND EXPERIMENTAL PROCEDURE}

\section{PROSA software}

To simulate the engine, the rotation was assumed being constant and then it was kept at $600 \mathrm{rpm}$. The mechanical power obtained was $6.8 \mathrm{~kW}$, and the efficiency $22.24 \%$ for (a) nominal engine load, (b) 40 bar pressure, (c) $60{ }^{\circ} \mathrm{C}$ compression temperature, and (d) $760{ }^{\circ} \mathrm{C}$ at hot heat-exchanger wall temperature. At this point, a thermal power of 27.44 $\mathrm{kW}$ was added to the Stirling engine (hot source) and an $18.26 \mathrm{~kW}$ thermal power rejected by the engine (cold source). Varying the software parameters, the curves shown in Fig. 3 and Fig. 4 were then obtained.

Figure 3 shows the variation of power and engine efficiency by raising the operating pressure at a fixed speed of $600 \mathrm{rpm}$. The Figure 4 shows the influence of rotation on mechanical power and on such engine efficiency for a constant pressure of 40 bars. In the curve shown in figure 4 , the behaviour of efficiency is increasing concerning engine load rise. According to the chart, the internal pressure should be roughly 47 bars to generate $8 \mathrm{~kW}$, as was initially proposed by the project. The efficiency, moreover, is over 20 $\%$ for any pressure over 10 bars.

The behavior of power for pressure (loading dock) is linear in the operating range of such engine. Also, the efficiency is nearly constant (ranging about $0.5 \%$ ) when the engine operates at partial loads.

Comparing the theoretical power data from PROSA to data from Mathcad, one can see that there is a greater distance among values of the engine operating at partial load (from $50 \%$ to $70 \%$ load), occurring variations until $10 \%$ for such values. However, when the engine near its rated load is assessed, such difference among values from Schmidt and from PROSA is reduced to less than $1 \%$. 


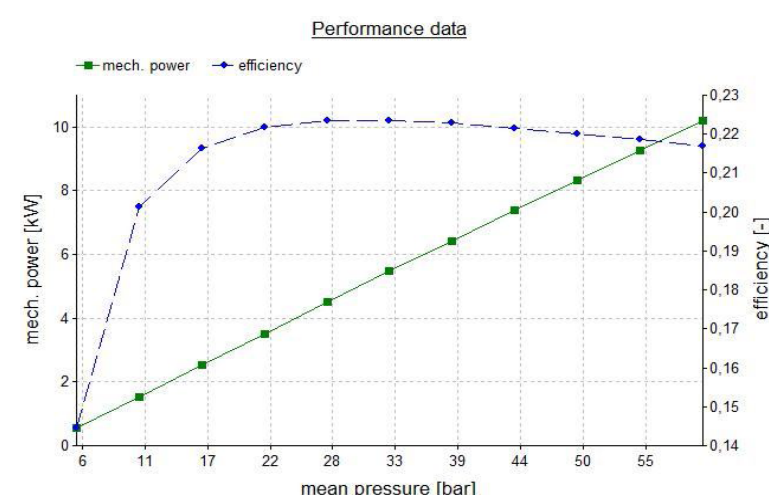

Figure 3. Internal engine pressure curves for the power and efficiency obtained by PROSA.

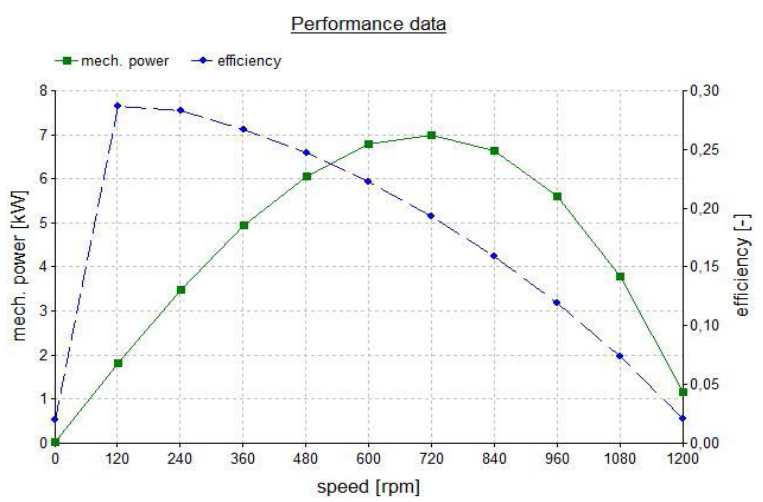

Figure 4. Influence of rotation for function based on mechanical power and efficiency.

Engine speed is another interesting assessment. Figure 4 shows the influence of this parameter for power and efficiency engine. For power, one can see an optimum point of roughly $720 \mathrm{rpm}$. After such point, when increasing the engine speed occurs a reduction in power. Concerning efficiency, the engine is more efficient to a rotation of $120 \mathrm{rpm}$, and the efficiency curve lessens when rising engine speed. In the chart, the optimum point for operation of such engine at $500 \mathrm{rpm}$, including a mechanical power of $6.4 \mathrm{~kW}$ and an efficiency of $24 \%$. By using the PROSA optimization tool, one can vary until 10 different parameters. Hence, keeping the constant rotation at $600 \mathrm{rpm}$, PROSA was asked to optimize the variables: (a) pressure inside the engine; (b) diameter, length, and porosity of regenerator; (c) hot and cold piston diameter; and (d) length and quantity of tubes for hot and cold exchangers. As a result, the values in Tab. 2 were obtained.

According to such results, the engine can generate $10.5 \mathrm{~kW}$ at efficiency of $33.49 \%$ for an internal pressure of 33 bars (figure 5), less than currently is used (40 bars). At this new operation point, we took $31.37 \mathrm{~kW}$ for thermal power added to the Stirling engine (hot source) and $14.88 \mathrm{~kW}$ for thermal power rejected by the engine (cold source). The figure 6 and 7 show the new relations between the engine operating pressure and the mechanical power and efficiency, as well as the influence of rotation on power and efficiency.

Table 2. Results to optimize PROSA parameters for the Amazon engine.

\begin{tabular}{|c|c|c|}
\hline $\begin{array}{c}\text { Variables selected for } \\
\text { optimization }\end{array}$ & $\begin{array}{c}\text { Initial } \\
\text { value }\end{array}$ & $\begin{array}{c}\text { Optimized } \\
\text { value }\end{array}$ \\
\hline Internal pressure (bar) & 40 & 34 \\
\hline Cold cylinder diameter (mm) & 177 & 197 \\
\hline Cold cylinder length (mm) & 325 & 177 \\
\hline $\begin{array}{c}\text { Quantity of tubes of cold } \\
\text { exchanger }\end{array}$ & 139 & 242 \\
\hline $\begin{array}{c}\text { Extensive regenerator } \\
\text { diameter (mm) }\end{array}$ & 130 & 290 \\
\hline $\begin{array}{c}\text { Regenerator length (mm) } \\
\text { Regenerator porosity (mm) }\end{array}$ & 0.78 & 0.64 \\
\hline Hot cylinder diameter (mm) & 177 & 235 \\
\hline $\begin{array}{c}\text { Length of tubes of hot } \\
\text { exchanger (mm) }\end{array}$ & 580 & 189 \\
\hline $\begin{array}{c}\text { Quantity of tubes of hot } \\
\text { exchanger }\end{array}$ & 169.0 & 193.1 \\
\hline
\end{tabular}

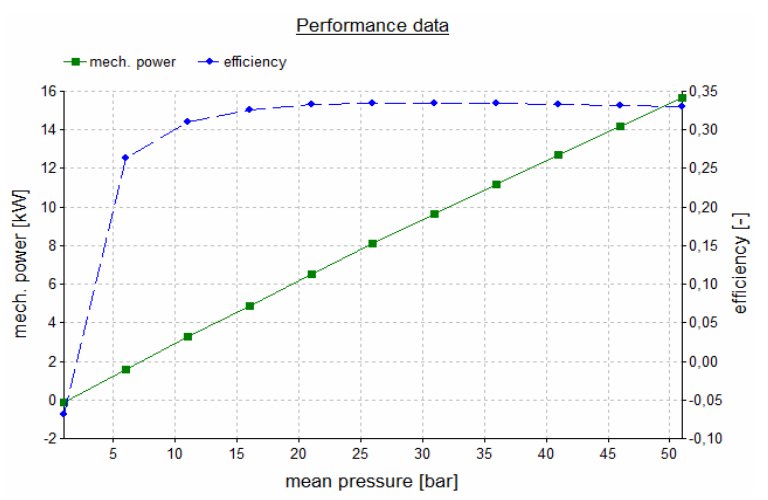

Figure 5. Internal engine pressure relations for the Amazon power and efficiency optimized by PROSA.

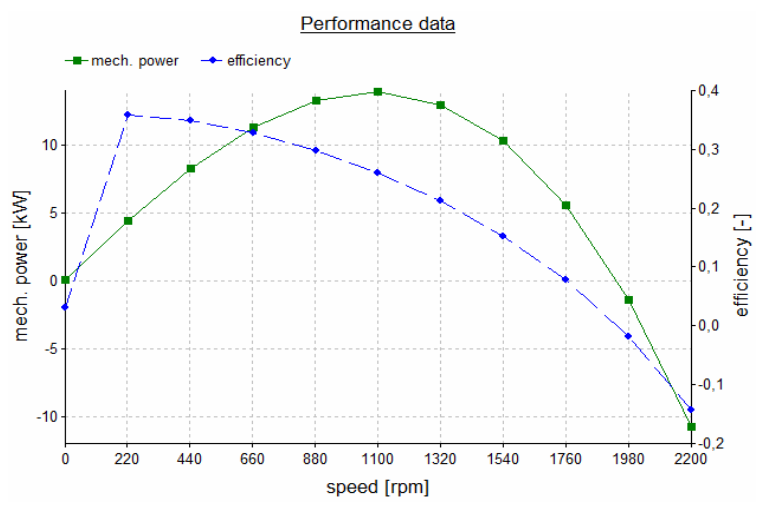

Figure 6. Influence of rotation on mechanical power and efficiency for the Amazon engine optimized by PROSA. 
Figure 6 shows that the engine has a maximum mechanical power in a rotation at $1100 \mathrm{rpm}$ and a maximum efficiency at $220 \mathrm{rpm}$. The best performance point is on a rotation of $660 \mathrm{rpm}$ with 11 $\mathrm{kW}$ and $33 \%$ of efficiency.

\section{Mathcad software}

As a result of this simulation software, the charts that relate the main parameters of engine operation and its main components with the rotation speed are shown in Fig. 7.

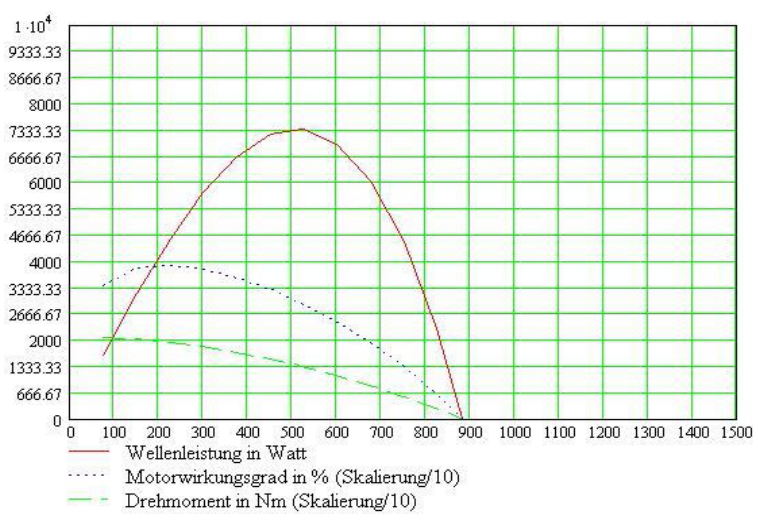

Figure 7. Shaft power, efficiency, and mechanical moment, all according to rotation speed.

Figure 7 shows a maximum power of $7.33 \mathrm{~kW}$ at $550 \mathrm{rpm}$, and the maximum speed without load is $900 \mathrm{rpm}$. At maximum power, the efficiency reaches $29 \%$. Higher efficiency values can be achieved at $230 \mathrm{rpm}$.

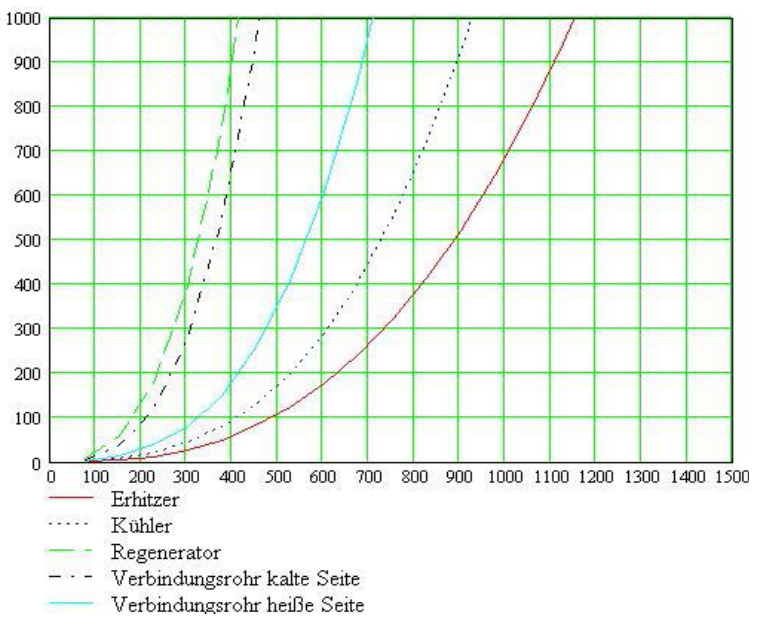

Figure 8. Load loss for working gas flow in the heater, cooler, regenerator, heater connection tubes, and cooler connection tubes, according to the operation speed.

Figure 8 shows the influence of operation speed for working gas flow losses. Such losses occur more frequently for the connection tubes between the hot cylinder and heater. Therefore, the manufacture of such element should promote an appropriate section and a smooth surface. The sum of the working gas flow losses are from $1900 \mathrm{~W}$ to $400 \mathrm{rpm}$.

\section{CONCLUSION}

As predicted theoretically, the results obtained by the Mathcad software were on average $6.8 \%$ higher than the results obtained by the PROSA software. Such fact occurs since Mathcad does not consider the losses in a real system. Hence, the PROSA is generally more accurate in its results. One can easily realize that modeling performed in Mathcad presents higher values for partial loads and similar values for the project operating point. Table 3 shows the comparison involving the major variables for theoretical operation of the Amazon Stirling engine.

Table 3. Comparison of the results for PROSA and Mathcad.

\begin{tabular}{|c|c|c|c|}
\hline \multicolumn{2}{|c|}{ Constants: pressure $=\mathbf{4 0}$ bar; rotation = 600 rpm } \\
\hline Variables & PROSA & Mathcad & $\begin{array}{c}\text { Difference (\%) } \\
\text { Mathcad/PROSA }\end{array}$ \\
Power (kW) & 6.8 & 7.0 & 2.9 \\
\hline $\begin{array}{c}\text { Efficiency (\%) } \\
\text { Heat absorbed } \\
\text { by the hot } \\
\text { heat/exchanger } \\
(\mathrm{kW})\end{array}$ & 22.2 & 24.0 & 7.9 \\
\hline $\begin{array}{c}\text { Heat absorbed } \\
\text { by the hot } \\
\text { cold/exchanger } \\
\text { (kW) }\end{array}$ & 18.4 & 16.0 & 3.9 \\
\hline
\end{tabular}

In general, the PROSA offers a more userfriendly graphical interface and the tools 'variation' and 'optimization', which allow a greater sensitivity assessment by users. In the future, the theoretical results presented here may be validated experimentally when the Amazon engine is properly working.

\section{ACKNOWLEDGEMENTS}

The authors thank CAPES and Programa de Recursos Humanos da Agência Nacional do Petróleo for financial support.

\section{REFERENCES}

Azzur, M., 2005. Comunicação pessoal. Acre. 
Betts, B., 2009, A Stirling idea [Stirling enginebased combined heat and power], Engineering \& technology, Vol. 4, No. 21, pp. 58-60.

Cullen, B. and McGovern, J., 2010, Development of a theoretical decoupled Stirling cycle engine, Simulation Modeling Practice and Theory, Vol. 19, pp. 1127-1234.

Jeng-Chyan, M.L., 2007, Combination of a Biomass Fired Updraft Gasifier and a Stirling Engine for Power Production, Journal of Energy Resources Technology, Vol 129, pp. 66-70.

Minassians, A. D. and Sanders, S. R., 2009, Multiphase Stirling Engines, Journal of Solar Energy Engineering, Vol. 131, No. 2, pp. 021013.1021013.11

Mahkamov, K., 2006, Design Improvements to a Biomass Stirling Engine Using Mathematical Analysis and 3D CFD Modeling, Journal of Energy Resources Technology, Vol. 128, pp. 203-215.

Mahkamov, K. 2007, Closure to "Discussion: 'Design Improvements to a Biomass Stirling Engine Using Mathematical Analysis and 3D CFD Modeling' Journal of Energy Resources Technology, Vol. 129, pp. $278-280$

Rogdakis, E. D. et al., 2002, Mathcad Program (AMOCO) as a Simple Tool for the Study of the Stirling Engines, 6th European Stirling Forum, Osnabrück, Germany.

Thomas, B. 2003. PROSA - Software for evaluation of Stirling engines cycle machines. Helpfile, version 2.3.2.

Received: July 30, 2011

Revised: August 30, 2011

Accepted: September 30, 201 